\title{
Yield of the admission complete blood count in medical inpatients
}

\author{
Benjamin Mozes, Yshai Haimi-Cohen and Hillel Halkin
}

\author{
Department of Internal Medicine, Sheba Medical Center, Tel Hashomer, Israel
}

\begin{abstract}
Summary: The clinical efficacy of routine admission complete blood count was evaluated in 302 patients admitted to internal medicine wards of a university teaching hospital. Patient medical problems, physical findings and medication history were evaluated by preset criteria to determine the proportion of tests performed for screening and the proportion of test results directly influencing patient management. Of the 282 complete blood counts performed, $\mathbf{8 0} \%$ were ordered routinely with no medical indications (screening tests). An haemoglobin abnormality was found in $16.7 \%$ of the patients, leucocyte abnormality in $16.1 \%$ and platelet abnormality in $4.6 \%$. However, these results directly influenced patient management in only one case $(0.14 \%)$. It is concluded that the utility of screening admission complete blood counts in medical inpatients is negligible.
\end{abstract}

\section{Introduction}

The use of various routine laboratory tests for screening purposes is common in patients admitted to hospitals. The yield of such admission case finding, evaluated for various laboratory tests such as the erythrocyte sedimentation rate, biochemical profile and urinalysis has been found to be very low despite a relatively large fraction of abnormal results. ${ }^{1-3}$ As the yield of the complete blood count as a routine admission test for patients hospitalized on nonsurgical services has not been studied to date, ${ }^{4}$ we conducted the present study to assess its utility in patients admitted to the internal medicine wards of a general hospital.

\section{Methods}

The study was conducted at the Chaim Sheba Medical Center, a major teaching hospital of the Tel-Aviv University Medical School. This centre has 266 internal medicine beds in 7 different wards. We studied all patients admitted to two internal medicine wards in June and July 1987. Emergency room patients accounted for $98 \%$ of the admissions. Every patient had the history taken and a complete physical examination as well as various laboratory tests including the complete blood count (haemoglobin, white blood cells and platelets) (Coulter Counter Model

Correspondence: B. Mozes, M.D., UCSF School of Medicine, Department of Laboratory Medicine, San Francisco CA 94143-0626, USA

Accepted: 20 February 1989
S-PLU). Data were collected within 72 hours of admission, from patient charts and laboratory reports and completed when needed by interviewing the staff physician. The data included: age, sex, active medical problems at admission, all physical findings, detailed medication history prior to admission and the routine test results. Tests were classified into two categories: those clearly indicated in the individual patient by the clinical findings according to preset criteria formulated for every test (see appendix), and those that were not indicated clinically, that is, were aimed for screening. The abnormal results (for normal ranges see appendix) of the screening tests were classified as those which could be explained on clinical grounds and those which were unexplained. Direct yield was defined as an abnormal test result which could have directly influenced patient management as assessed by a senior physician who was not involved in medical management on the study wards.

\section{Results}

The study included 302 consecutive patients of mean age 66.7 years. Results of $6.3 \%$ of the admission tests were not accounted for because of technical difficulties in the laboratory.

Most of the admission tests were classified as screening tests (Table I). As opposed to a relatively high proportion of abnormal results among the indicated tests $(78.6 \%, 45.2 \%$, and $44.5 \%$ for the haemoglobin levels, leucocyte counts and platelet counts respectively) much lower proportions of abnor- 
Table I Admission tests

\begin{tabular}{|c|c|c|c|c|c|c|c|c|c|c|c|}
\hline \multirow[b]{2}{*}{ Test } & \multirow{2}{*}{$\begin{array}{c}\text { No. of } \\
\text { patients } \\
\text { in sample }\end{array}$} & \multicolumn{2}{|c|}{$\begin{array}{l}\text { No. of } \\
\text { tests in } \\
\text { sample }\end{array}$} & \multicolumn{2}{|c|}{ Indicated } & \multicolumn{2}{|c|}{ Screening } & \multicolumn{2}{|c|}{$\begin{array}{c}\text { Indicated } \\
\text { abnormal } \\
\text { results }\end{array}$} & \multicolumn{2}{|c|}{$\begin{array}{c}\text { Screening } \\
\text { abnormal } \\
\text { results }\end{array}$} \\
\hline & & No. & $\%$ & No. & $\%$ & No. & $\%$ & No. & $\%$ & No. & $\%$ \\
\hline Haemoglobin & 302 & 283 & 93.7 & 61 & 21.6 & 222 & 78.4 & 48 & 78.6 & 37 & 16.7 \\
\hline Leucocytes & 302 & 283 & 93.7 & 84 & 29.7 & 199 & 70.3 & 38 & 45.2 & 32 & 16.1 \\
\hline Platelets & 302 & 282 & 93.4 & 22 & 7.9 & 260 & 92.1 & 10 & 44.5 & 12 & 4.6 \\
\hline
\end{tabular}

mal results were found among the screening tests (Table I). The rate of direct yield of the tests indicated on clinical grounds was $14.4 \%, 22.6 \%$ and $4.5 \%$ respectively. Among the screening tests we found only one instance in which the test resulted in direct clinical yield.

Nearly all $(97 \%)$ the screening haemoglobin levels were above $10 \mathrm{~g} / \mathrm{dl}$. Most ( $70 \%)$ of these patients were women 60 years of age and older. One patient had mild secondary polycythaemia. The only patient in whom the haemoglobin was lower than $10 \mathrm{~g} / \mathrm{dl}$ was an 86 year old severely demented patient with a level of $9.3 \mathrm{~g} / \mathrm{dl}$. Most of the leucocyte counts $(85 \%)$ were below $15 \times 10^{9} / 1$ and not even one resulted in direct yield. Among the screening abnormal platelet counts only one result directly influenced patient management - in a case of thrombocytopenia (without purpura) in a patient on quinidine.

\section{Discussion}

Our main findings were a high proportion of tests with direct yield among those indicated on clinical grounds, as opposed to negligible yield for admission screening tests despite a high rate of abnormal results. As our study was not designed as a prospective follow-up study we could not prove that these tests had no value in our patients. However, there is substantial evidence in the literature that most of these clinically unexplained abnormal results are caused by definitions of the normal range which are based on inappropriate sampling. ${ }^{5-7}$ Several evaluations of the complete blood count as a screening measure for case finding in the pre-admission stage, have been published. Kaplan et al. ${ }^{8}$ reviewed the results of 610 preoperative tests, $48 \%$ of which were not indicated. Two were abnormal and none were judged to have been clinically significant.

Shapiro et al. ${ }^{9}$ used criteria for appropriate indications for the differential white cell count to evaluate its utility in a university hospital setting. None of the 295 not indicated tests led to changes in diagnosis or in therapy.

More extensive evaluations have been aimed at the utility of the preadmission biochemical profile. All these studies have found relatively high rates of unexpected abnormal results which were higher on medical as opposed to surgical services. Routine biochemical profile tests led to the identification of significant new medical diagnoses in $4 \%-10 \%$ of the total. However, early diagnosis had no clinical relevance in most of the conditions uncovered. ${ }^{10,11}$ Two controlled studies ${ }^{12,13}$ have found no advantage in the management of screened, as opposed to unscreened patients, while the screening process added a $5 \%$ increment to hospital costs.

Detection of disease is highly dependent on its prevalence in the tested population. In our study the patients defined as the screened population had been selected out by proven clinical criteria. Therefore low prevalence of disease (which can be detected by complete blood count) and low yield of test results were fully expected.

Screening tests may also have negative effects beyond contributing to the rising costs of medicine. The sheer volume of numerical results may dilute the significance of the individual results, causing important findings to be overlooked in the mass superfluous data. ${ }^{14}$ Finally the uncovering of an abnormal result (mostly not beneficial for the patient) is often associated with a labelling effect and causes unnecessary anxiety and absenteeism from work. ${ }^{15}$ We conclude that complete blood count need not be part of admission screening in medical inpatients and should be ordered only when indicated by clinical findings. We believe this recommendation could reduce expenditures without detrimental effect on direct inpatient management.

\section{Appendix}

Indication for ordering:

\section{Haemoglobin}

Overt bleeding, physical findings such as: pallor, hypotension, orthostatic hypotension, tachycardia, jaundice, splenomegaly, flush, lymphadenopathy, cachexia, anamnestic details such as: weakness, deterioration of functional capacity without known reason, changes in bowel habits, pregnancy; follow-up of patients with anaemia. 
Leucocyte counts

Fever, suspected infection or sepsis, lymphadenopathy, follow-up of patients with myeloproliferative diseases.

\section{Platelet counts}

Spontaneous bleeding without probable cause; new onset purpura, petechiae or ecchymoses, suspected sepsis.

\section{References}

1. Kovrin, C.C., Pearce, R.H. \& Stanley, J. Admissions screening: clinical benefits. Ann Intern Med 1975, 83: 197-203.

2. Sox, H.C. \& Liang, M.H. The erythrocyte sedimentation rate. Ann Intern Med 1986, 104: 515-523.

3. Akin, B.V., Hubbel, F.A., Frye, E.B., Rucker, L. \& Friis, R. Efficacy of the routine admission urinalysis. Am J Med 1987, 82: 719-722.

4. Shapiro, M.F. \& Greenfield, S. The complete blood count and leukocyte differential count. Ann Intern Med 1987, 106: 65-74.

5. Osgood, E.E. Normal hematologic standards. Arch Int Med 1935, 56: 849-863.

6. Wintrobe, M.M. Blood of normal men and women: erythrocyte counts, hemoglobin and volume of packed red cells of 229 individuals. Bull Johns Hopkins Hosp 1933, 55: 118-130.

7. Judy, H.E. \& Price, N.B. Hemoglobin level and red blood cell count findings in normal women. JAMA 1958, 167: $563-566$.

8. Kaplan, E.B., Sheiner, L.B., Boecmann, A.J. et al. The usefulness of preoperative laboratory screening. JAMA 1985, 253: 3576-3581.
Normal ranges

\begin{tabular}{lcc}
\hline & Males & Females \\
\hline Haemoglobin & $14-18 \mathrm{~g} / \mathrm{dl}$ & $12-16 \mathrm{~g} / \mathrm{dl}$ \\
Leucocytes & $4-10 \times 10^{9} / 1$ \\
Platelets & $10-44 \times 10^{10} / 1$
\end{tabular}

9. Shapiro, M.F., Hatch, R.L. \& Greenfield, S. Cost containment and labor intensive tests: the case of the leukocyte differential count. JAMA 1984, 252: 231-234.

10. Bryan, D.J., Wearne, J.L., Viau, A., Musser, A.W., Schoomaker, F.W. \& Thiers, R.E. Profile of admission chemical data by multichannel automation: an evaluation experiment. Clin Chem 1966, 12: 137-143.

11. Bellivear, R.E., Fitzgerald, J.E. \& Nickerson, D.A. Evaluation of routine profile chemistry screening of all patients admitted to a community hospital. Am J Clin Pathol 1970, 53: 447-451.

12. Whitehead, T.B. \& Wootton, I.D.P. Biochemical profiles for hospital patients. Lancet 1974, ii: 1439-1443.

13. Durbridge, T.C., Edwards, F., Edwards, R.G. \& Atkinson, M. Evaluation of benefits of screening tests done immediately on admission to hospital. Clin Chem 1975, 22: $968-971$.

14. Whitby, L.G. In: Williams, R. (ed.) 5th Symposium on Advanced Medicine. Pitman Medical, London, 1969, p. 279.

15. Haynes, R.B., Sacket, D.L., Taylor, D.W., Gibson, E.S. \& Johnson, A.L. Increased absenteeism from work after detection and labelling of hypertensive patients. $N$ Engl $J$ Med 1978, 299: 741-744. 